\title{
LA CONSTRUCCIÓN DEL MERCADO DE ARTE EN COSTA RICA: POLÍTICAS CULTURALES, ACCIONES ESTATALES Y COLECCIONES PÚBLICAS (1950-2005). E. ZAVALETA OCHOA (2019). SAN JOSÉ, COSTA RICA: EUCR
}

Rafael Cuevas Molina

Recibido: 14/05/19 - Aceptado: 27/05/19

Eugenia Zavaleta nos ofrece, en La construcción del mercado de arte en Costa Rica: Políticas culturales, acciones estatales y colecciones públicas (1950-2005), un estudio pormenorizado no solo de lo que constituye el objeto central de su estudio sino, más en general, del papel que jugó el estado de bienestar en la conformación de lo que considero que con propiedad podríamos llamar la identidad cultural contemporánea en el país.

Efectivamente, como ha sido documentado cada vez con mayor profusión, esa identidad, que hoy se encuentra nuevamente en un período de reconfiguración acelerado, ha tenido en Costa Rica al Estado como su artífice mayor desde el momento mismo de la configuración de la república, pero especialmente a partir del último tercio del siglo XIX, cuando se toma conciencia del valor utilitario que tiene para la política aglutinar a la ciudadanía en torno a un ideal común, que resalta valores y rasgos acordes con un determinado proyecto de desarrollo, en este caso el de los liberales.

En este contexto, el arte y la literatura han jugado siempre un papel relevante, al concretar los rasgos que dan forma reconocible e identificable a los etéreos valores que se imaginan como representativos. Himnos, estatuas, obras de arte, cuentos, novelas y poemas van perfilando en personajes, paisajes, colores, ambientes y sonidos, un universo que, en su conjunto, se identifica con una forma singular e irrepetible de ser colectiva.

En Costa Rica, ha habido un creciente interés por estudiar estos aspectos desde hace unos quince o veinte años, pero especialmente en los últimos diez años. A vuelo de pájaro, y solo a manera de ejemplo, podemos mencionar algunas investigaciones y autores: en el ámbito de la música, los trabajos de María Clara Vargas Cullel, especialmente De las fanfarrias a las salas de concierto. Música en Costa Rica (1840-1940); de Tania Vicente Hurtándole tiempo al tiempo. La música académica en el Valle Central: de oficio a profesión (1940-1972) y, en conjunto con Zamira Barquero, Mujeres costarricenses en la música. 
Las investigaciones doctorales, con implicaciones centroamericanas, de Nuria Zúñiga La construcción y consolidación del campo de producción guitarrístico centroamericano; de Luis Monge Raíces africanas presentes en la obra musical de Luis Enrique Mejía Godoy, Walter Ferguson y Rubén Blades; de Gerardo Meza Tres compositores centroamericanos del Centro de Altos Estudios Musicales del Instituto Torcuato di Tella; de Jorge Carmona Sonatas para piano de construcción serialista en Centroamérica (1980-1997).

En danza, los trabajos de Marta Ávila; en teatro los de Patricia Fumero, entre los que cabe mencionar Teatro, público y Estado en San José (1880-1914). En literatura La casa paterna. Escritura y nación en Costa Rica, de Flora Ovares, Margarita Rojas, Carlos Santander y María Elena Carballo; Literatura de Kiosko. Revistas literarias de Costa Rica (1890-1930) de Flora Ovares; y en las artes visuales las investigaciones de María José Monge Relaciones constituyentes; la de Gabriela Sáenz, que ganó el Premio Nacional Luis Ferrero Acosta de Investigación Cultural del 2018, El coleccionismo estatal de artes visuales en Costa Rica y sus narrativas, 1950-2006; de la misma Eugenia Zavaleta Las exposiciones de artes plásticas (1928-1937) en Costa Rica, y los trabajos de investigación que, como curador, ya sea del Museo de Arte Costarricense o de otras instituciones, ha realizado José Miguel Rojas.

Estos trabajos relativamente recientes, que en esta lista sucinta e incompleta nombramos, han permitido determinar algunas constantes que caracterizan a la dinámica cultural costarricense, y que le otorgan especificidad. Seguramente la más relevante es la del papel determinante que siempre ha tenido el Estado como su gestor y director principal; un Estado en cuyo seno los grupos dominantes siempre entendieron a la cultura como un espacio determinante para el ejercicio de su hegemonía. En tal sentido, dentro de sus posibilidades y condiciones históricas particulares, siempre impulsaron lo que hoy llamamos políticas culturales, incluso cuando esa noción no existía, y aunque muchos y muchas investigadores no coincidan con esta apreciación, porque piensan que estas tuvieron su génesis hasta la segunda mitad del siglo XX, cuando se perfila el tipo de Estado que llamamos Benefactor o Social.

El trabajo de Eugenia Zavaleta se suma a esta lista de estudios que va desentrañando paulatinamente esos rasgos caracterizadores, abordando un aspecto puntual que, no por serlo, deja de iluminar el todo. Abarca un extenso período, en el que se suceden dos momentos históricos que están en la base del momento que vivimos actualmente: el del Estado Benefactor y el del quiebre hacia el modelo neoliberal, en el que nos encontramos ahora.

Algo que tienen en común todos estos trabajos es la comprensión de la dinámica de la cultura, y sus específicas concreciones y expresiones, como formando parte intrínseca de un todo social que en mayor o menor medida le otorga sentido. A pesar que en los referentes teóricos que les sirven de sustento son muy variados, aparece siempre, de forma directa o indirecta, la propuesta teórico-conceptual del sociólogo francés Pierre Bourdieu, quien para sus investigaciones de la cultura francesa de la 
segunda mitad del siglo XX construyó un conjunto de herramientas teóricas, entre las que sobresale la de campo cultural.

El estudio de Zavaleta comparte también, con el resto de trabajos mencionados, un hálito de nostalgia por lo que fue y ya no es, es decir, por esos años en los que había tras la acción del Estado eso que José Figueres Ferrer, una de sus figuras emblemáticas, enunció de forma sintética en varias ocasiones: que nos cuidáramos de no llegar a ser un país con altos índices de desarrollo pero vulgar.

Dos cosas deben precisarse una vez dicho lo anterior. La primera es que Zavaleta no enuncia abiertamente, en ninguna parte de su trabajo, tal actitud nostálgica; por eso he preferido usar el término "hálito" para referirme a esa idea que queda rondando en el lector al concluir el repaso de su obra. La segunda es que, sin que en ninguna parte, tampoco, se haya enunciado negro sobre blanco tal idea, flota entre la intelectualidad costarricense la idea de que la cultura en Costa Rica, de alguna forma, vivió una "edad de oro" que, seguramente, habría tenido su cúspide en los años setenta del siglo XX.

Es precisamente en ese período cuando el estudio que nos ocupa sitúa el nacimiento del mercado del arte en el país, entendiéndolo como un fenómeno complejo, que va más allá que la simple transacción mercantil de obras de arte. Es el momento en el que el Estado se preocupa, acorde con su concepción del papel que debía jugar la cultura en la sociedad, por "llevar el arte al pueblo", lo que lo lleva a iniciar el proceso de formación tanto de un público que, eventualmente, podría funcionar como consumidor, como de un cuerpo, cada vez más profesionalizado, de creadores y creadoras.

Para eso, el Estado creó un aparato institucional orientado hacia la cultura sin parangón en la región, aparato que fue creación y, al mismo tiempo sustento, de lo que aquí llamaré una intelectualidad orgánica socialdemócrata, cuya caracterización fue esbozada inicialmente allá por los lejanos años 70 por Jorge Valdeperas, en su libro Para una interpretación de la literatura costarricense, en donde les llamó "los hombres de letras del Partido Liberación Nacional" y que hoy, acorde con las nuevas sensibilidades sociales prevalecientes, no restringiríamos a "los hombres" puesto que, en estricto sentido, abarcó figuras como las de Carmen Naranjo, Inés Trejos o Zulay Soto, que formaron equipo con otras masculinas como Alberto Cañas, Guido Sáenz, Rafael Ángel "Felo" García o César Valverde, cuya presencia se encuentra profusamente presente en las fotografías que acompañan a este estudio.

Ese aparato institucional, multiforme y cada vez más amplio, se vio también acompañado por una prolífera legislación sustentadora de la acción estatal, propia de otra característica específicamente costarricense en la región, como es la del apego a un Estado de derecho que implica la reglamentación rigurosa y precisa que ordena y regula, lo que dio como resultado un cuerpo legislativo que, por sus dimensiones y complejidad, dio pie a que Zavaleta le dedicara un capítulo entero de su trabajo. 
La quiebra, fracaso o agotamiento, como quiera llamársele, del estado de bienestar en Costa Rica a finales de los años setenta, abrió las puertas para lo que pienso que podría llamarse con toda propiedad una "refundación" del Estado. Esa refundación implicó, como bien lo apunta nuestra autora, la búsqueda de formas a través de las cuales el aparato del Estado se desembarazara de muchas de las obligaciones que había asumido con anterioridad. El uso del término "desembarazarse", para referirse al proceso que concreta la desiderata neoliberal de achicamiento del Estado, no lo usa Zavaleta, pero creo que sorprende una de las tendencias centrales que caracterizan a la dinámica de la cultura costarricense a partir de los años ochenta hasta nuestros días.

Este nuevo modelo de organización social tuvo implicaciones en el mercado del arte. Su dinámica, marcada hasta entonces casi exclusivamente por el ritmo y la legitimidad que le otorgaban las iniciativas que emanaban de la pujante institucionalidad oficial, se vio pronto acompañada por la irrupción de distintas formas de lo privado. Las fundaciones, por ejemplo, se convirtieron en fiscalizadoras, administradoras y, en algunas ocasiones, orientadoras de la acción de museos y complejos culturales emblemáticos del arte y la cultura costarricense.

El nuevo rumbo adoptado se puede resumir en las palabras de la directora de una de estas instituciones en cuestión, y que Zavaleta cita en su trabajo: se "eliminaría el preconcepto de que la cultura es gratis; pues -más bien- esta debe ser rentable y se debe pasar la factura a las comunidades que la usan, al público que tiene acceso a estos bienes" (Zavaleta 240).

Un campo cultural crecientemente profesionalizado por la acción del Estado en el ámbito de la formación universitaria, incentivado por la legitimación otorgada por las continuas actividades que las instituciones estatales habían organizado para hacer circular las propuestas de las y los creadores, y el coleccionismo que habían promovido y respaldado con la legislación del caso, estaba suficientemente maduro para que afloraran galerías privadas que aprovecharon las condiciones creadas en las décadas anteriores. La posesión de obras de creadores como Rafa Fernández y César Valverde, que habían surgido y se habían afianzado al amparo de la institucionalidad estatal, se convirtieron en símbolo de estatus para ciertos grupos económicamente acomodados del Área Metropolitana.

Es interesante observar, sin embargo, una corriente paralela a la del Estado, que Eugenia Zavaleta no toca específicamente en su estudio, pero a la que debería prestársele mayor atención, que tiene a Fernando Carballo como uno de sus más conspicuos exponentes, y que tiene un recorrido que debe asociarse a instituciones propias de un aparato distinto y contestatario al estatal. En torno a este campo cultural alternativo florece también una intelectualidad y, más en general, una sensibilidad muchas veces paralela a la oficial, a la que no le es tan fácil acceder a la legitimidad del aparataje del Estado, como los premios, por ejemplo, que legitiman y por lo tanto posicionan en el ámbito del estatus, pero que ha creado sus propios mecanismos para adaptarse a las 
circunstancias regidas por el mercado que se hacen presentes especialmente desde los años 80. Esta intelectualidad, también orgánica, pero en relación a diferentes fuerzas sociales a las que impulsaron el desarrollo oficial costarricense después de la Guerra Civil de 1948, no tiene tanta capacidad adquisitiva. Son, como dice en la investigación de Zavaleta un galerista entrevistado, "sectores medios que aprecian y disfrutan de las obras de arte, pero sus elevados precios les impiden adquirirlas" (184), por lo que las y los creadores deben adaptar sus técnicas y sus precios. Proliferan por lo tanto, en este campo alternativo, el grabado, la serigrafía y otras formas de reproducción gráfica.

Como vemos, la investigación a la que nos referimos estimula las posibilidades de profundización en múltiples aristas que se han ido perfilando en la Costa Rica de los últimos sesenta años. Otra, que no querría dejar de mencionar, es el de la creciente presencia de creadores y creadoras jóvenes, generalmente con formación universitaria en el campo de las artes, a quienes el Estado les propone hoy en día la opción del emprendedurismo, que ha creado un mercado a veces más informal, en el que se incluye lo que podríamos catalogar como novo artesanía aunque no solo, que transita entre ferias y museos, cristalizando algunas veces en lo que es la desiderata suprema de la propuesta del Estado neoliberal en el orden de la cultura: el pequeño negocio, hoy llamado "emprendimiento", que ofrece propuestas que oscilan entre las corrientes más contemporáneas de las artes visuales, las manualidades, el diseño, la pintura y la escultura, y cuyos productos permiten que consumidores de clase media ofrezcan a sus congéneres muestras de sensibilidad y refinamiento que los hace aparecer como diferentes.

Todos estos aportes que nos ofrece Eugenia Zavaleta están sustentados en un exhaustivo trabajo de fuentes. De las cuatrocientas páginas que tiene el libro, 100 son dedicadas a mostrarlas, sin que entre a hacer ninguna consideración específica sobre ellas, y los cuadros que aparecen en los 16 anexos permiten sistematizar una vasta información que, presentada de esa forma, ofrecen una síntesis que reafirma lo expuesto en el texto precedente.

Se trata, pues, de un trabajo de gran calado que, con seriedad académica, viene a apuntalar y darle un impulso más, al creciente interés por la investigación de la dinámica cultural y artística del país.

Rafael Cuevas Molina. Costarricense. Profesor investigador del Instituto de Estudios Latinoamericanos de la Universidad Nacional, Costa Rica. Doctor en Historia y autor de libros y artículos sobre la dinámica de la cultura en Costa Rica, Centroamérica y América Latina.

Contacto: rcuevas_cr_2000@yahoo.es

ORCID: 0000-0001-7038-8301 
